\title{
Sporadic Giant Mesenteric Fibromatosis
}

\author{
Snita Sinukumar • Rachel M. Gomes • Rajiv K. Kumar • \\ Ashwin Desouza • Avanish Saklani
}

Received: 13 December 2013 / Accepted: 28 July 2014 / Published online: 2 August 2014

(C) Indian Association of Surgical Oncology 2014

\begin{abstract}
Mesenteric fibromatosis is an uncommon tumour which is locally aggressive without any metastatic potential and can occur as a sporadic event or in association with familial adenomatous polyposis syndrome. Giant mesenteric fibromatosis is very rare and is a diagnostic and therapeutic challenge. This is a case report of a rare presentation of deep fibromatosis as a sporadic giant intrabdominal mesenteric tumour in a 29 year old male managed by surgical excision and definitive diagnosis made on the basis of immunohistochemical findings.
\end{abstract}

Keywords Desmoid tumors · Mesenteric fibromatosis · Familial adenomatous polyposis

\section{Introduction}

Deep fibromatosis are soft tissue tumours of mesenchymal origin with a propensity to infiltrate and recur locally with minimal potential for distant metastasis. [1] Intra abdominal fibromatosis have a tendency to cause morbidity from bowel compression, perforation or tumour rupture and haemorrhage. [2] The mesentery remains the most common site of occurrence of intra abdominal fibromatosis. The etiology is unknown with genetic, trauma, surgery and hormonal factors being implicated. These tumours may arise sporadically or in association with familial adenomatous polyposis syndrome (FAP). [3, 4]. Differential diagnosis from similar tumours

S. Sinukumar $\cdot$ R. M. Gomes $\cdot$ A. Desouza $\cdot$ A. Saklani $(\triangle)$ Unit of Colorectal Surgery, Department of Surgical Oncology, Tata Memorial Hospital, E Borges RoadParel Mumbai 400 012, India e-mail: asaklani@hotmail.com

\section{R. K. Kumar}

Department of Pathology, Tata Memorial Hospital, Mumbai, India has important clinical implications and can only be done by immunohistochemical evaluation. The management of mesenteric fibromatosis is challenging and various surgical and non surgical modalities are suggested as part of the treatment armamentarium. [5]

\section{Case Report}

A 28 year old gentleman presented with history of a slowly growing abdominal lump associated with vague abdominal pain of 10 months duration. He had no past history of colonic polyps or abdominal trauma or any other significant family history.

Abdominal examination revealed a very large, firm, non tender, globular abdominal mass encompassing the entire abdomen. His routine laboratory investigations were within normal limits. A contrast enhanced CT scan of the abdomen revealed a $21 \times 12 \mathrm{cms}$ homogenously enhancing mass extending from the subyloric region cranially to the dome of the bladder caudally with blood supply derived from the terminal branches of the superior mesenteric artery. The tumour was compressing upon the inferior vena cava but the planes with the inferior vena cava, superior mesenteric artery and superior mesenteric vein and the other blood vessels were maintained (Fig. 1a, b). A preoperative CT guided biopsy was done and showed a spindle cell tumour suspicious for fibromatosis. Although he had no family history suggestive of FAP, a full colonoscopy was performed to rule out any colorectal polyps, which revealed no abnormality.

Laparotomy revealed a $20 \times 20 \mathrm{cms}$ mass occupying the entire abdomen originating from the small bowel mesentry with the terminal $60 \mathrm{cms}$ of the ileum infiltrated by the mass. The mass was excised with the terminal ileum, caecum and part of ascending colon followed by an ileo- ascending anastomosis. Post operative course of the patient was uneventful 
Fig. 1 Contrast enhanced computed tomography scan showing a huge heterogenous mass occupying almost whole of the abdomen and pelvis showing compression of the IVC. a: axial section venous phase $\mathbf{b}$ : axial sections arterial phase
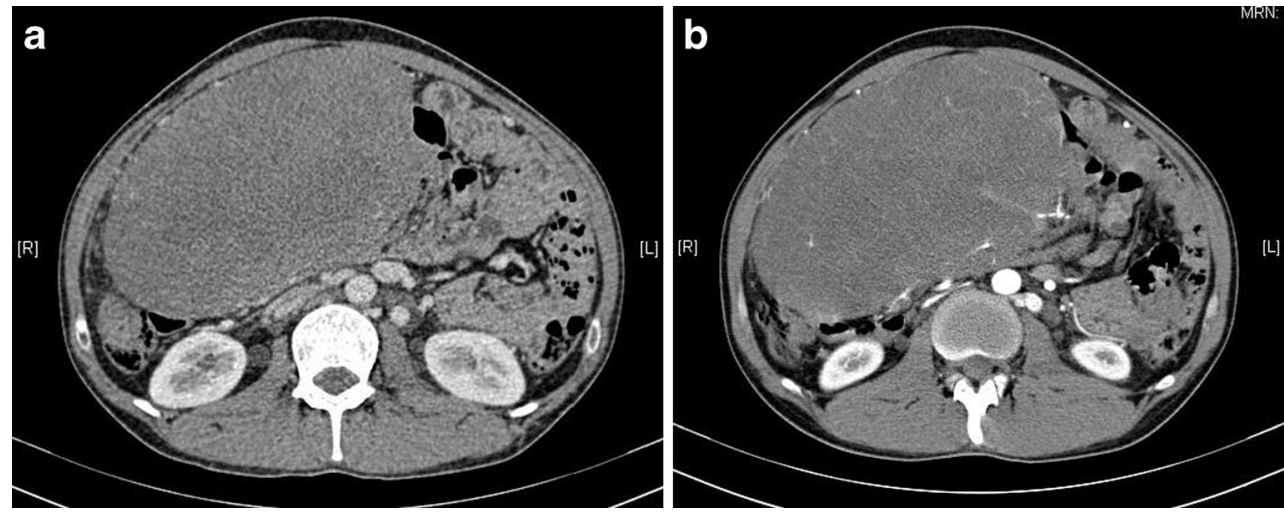

On pathological examination a well encapsulated $30 \times 21 \times$ $12 \mathrm{cms}$ tumour was seen in the mesentery of small intestine. Cut surface was glistening firm grey white, with no areas of haemorrhage or necrosis (Fig. 2a, b). Microscopically, the lesion was composed of cytologically bland spindle-shaped or stellate cells evenly deposited in a densely collagenous stroma and showed variable cellularity (Fig. 3a, b). Interspersed were few thin walled ectatically dilated blood vessels. Muscularis propria of intestine was uninvolved. Immunohistochemistry was positive for beta catenin, and negative for cKit, CD34, desmin and smooth muscle actin (Fig. 3c, d).

\section{Discussion}

Fibromatosis or desmoid tumors are rare tumors comprising less than $3 \%$ of all soft tissue sarcomas and about $0.03 \%$ of all malignancies. They can affect both superficial and deep parts of the body. The deep intra abdominal variant most commonly affects the small bowel mesentry with an annual incidence of 2-4 cases/million population. [6] Fibromatosis or desmoid tumors manifest most commonly between the age group of 15 to 60 years without any gender predilections. However intra abdominal fibromatosis are most frequently found in young adults with a peak incidence at 30 years. [7]
The etiopathogenesis remains obscure. Genetic factors with germ line mutations in APC gene have been implicated in the familial or hereditary form of mesenteric fibromatosis however sporadic desmoid tumors may also harbour a somatic mutation in the APC gene and/or the beta -catenin gene. Prior abdominal surgery, trauma and hormonal stimulation have also been implicated in tumorigenesis. $[6,8]$

Patients usually present with myriad clinical features varying from an insidiously growing mass to presentations with features of bowel obstruction like vomiting, constipation, weight loss or ureteric obstruction or as surgical emergencies like gastrointestinal bleeding, mesenteric ischaemia, bowel perforation or tumour rupture. $[4,9]$

The radiological features of this tumour are variable CT scan or MRI are the mainstay imaging modalities. They help to determine the site, size, extent of the lesion and degree of local invasion. Mesentric fibromatosis are seen as well circumscribed homogenous masses. On CT they are generally hypodense. Contrast enhancement and attenuation is variable and usually correlates with the collagenous or myxoid matrix content of the tumor. [9]. This is in contrast to GIST which is a close differential diagnoses which shows heterogenous enhancement with evidence of necrosis, calcification with or without bowel infiltration and lymphnode metastasis. MRI may be used where CT scan is contraindicated.
Fig. 2 a Photograph of resected specimen along with attached segment of bowel b Cut surface showing grey white tumour with no areas of haemorrhage or necrosis
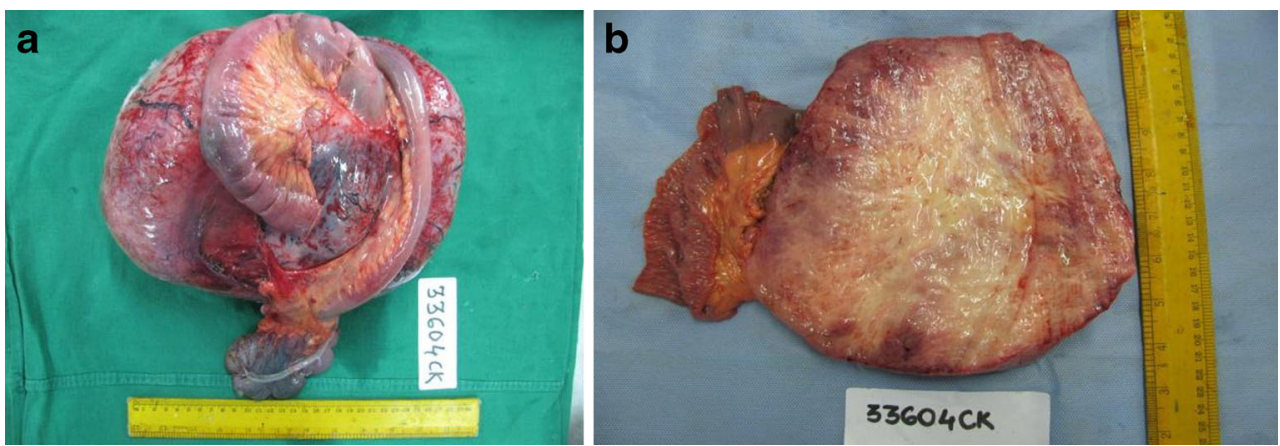
Fig. 3 Histological examination shows neoplasm composed of haphazardly arranged spindle or stellate shaped cells in a collagenous stroma with bland cytomorphological details (a),(b): Hematoxylin and eosin stain (H\&E; 100x \& 400x) (c) Positive beta catenin immunostaining (100x) (d) Negative CD34 immunostaining $(100 \mathrm{x})$


Definitive diagnosis is established by pathological features. The closest differential diagnosis include GIST, solitary fibrous tumor, inflammatory myofibroblastic tumours. The distinguishing histopathological characteristics of these tumours are summarized in Table 1.

The management of mesenteric fibromatosis is challenging. Surgery remains the main treatment modality. One must endeavour to resect the tumour with negative surgical margins without significantly adding to morbidity. Microscopically positive margins have shown to predict local recurrence in various studies [10]. Adjuvant radiation therapy reduces recurrence of mesenteric fibromatosis to 20 $40 \%$, compared to $40-70 \%$ with resection alone. Besides surgery, pharmacological agents including anti estrogens, nonsteroidal anti-inflammatory drugs (NSAIDs) and cytotoxic chemotherapy with dactinomycin, vincristine and cyclophosphamide, singly or in combination have been used. Various rates of partial and complete response have been reported ranging from 19 to $50 \%$. [5]

In conclusion, mesenteric fibromatoses have a varied clinical presentation. Imaging aids diagnosis and helps planning a possible surgical treatment. Immunohistochemical features confirms the diagnosis and differentiates from other similar tumours. Wide surgical excision remains the mainstay in treating these tumours. Numerous non surgical modalities have been explored with varying results.

Table 1 Histopathological characteristics of the common differential diagnosis of mesenteric fibromatosis

\begin{tabular}{|c|c|c|c|}
\hline Differential diagnosis & Gross features & Histopathological features & $\begin{array}{l}\text { Immunohistopathological } \\
\text { features }\end{array}$ \\
\hline Mesentric fibromatosis & $\begin{array}{l}\text { Tan gray masses with infiltrative margins and } \\
\text { homogenous parenchyma without any } \\
\text { hemorrhagic, cystic or necrotic changes }\end{array}$ & $\begin{array}{l}\text { Monotonous spindle cells growing in long, } \\
\text { sweeping fascicles Minimal or complete } \\
\text { absence of mitotic activity }\end{array}$ & $\begin{array}{l}\text { Vimentin, B-catenin } \\
\text { positive, negative } \\
\text { for CD34,c-kit }\end{array}$ \\
\hline Solitary fibrous tumor & $\begin{array}{l}\text { Well defined masses with firm, pale cut surface } \\
\text { showing whorled fibrous tissue. }\end{array}$ & $\begin{array}{l}\text { Scarce cellularity increase vascularity. } \\
\text { showing hyalanization. }\end{array}$ & $\begin{array}{l}\mathrm{CD} 34, \mathrm{CD} 99 \text { and } \mathrm{Bcl}-2 \\
\text { positive }\end{array}$ \\
\hline GIST & $\begin{array}{l}\text { Expansive,firm, pale multilobulated soft masses } \\
\text { associated with areas hemorrhagic, cystic and } \\
\text { necrotic changes }\end{array}$ & $\begin{array}{l}\text { Spindle and epitheloid cells with organoid } \\
\text { cellular arrangement. Varying degree of } \\
\text { mitosis present with or without atypia. }\end{array}$ & $\begin{array}{l}\text { c-kit } \mathrm{CD} 117, \mathrm{CD} 34 \\
\text { positive, negative for } \\
\text { beta catenin }\end{array}$ \\
\hline $\begin{array}{l}\text { Inflammatory } \\
\text { Myofibroblastic tumour. }\end{array}$ & $\begin{array}{l}\text { Non encapsulated, circumscribed nodular } \\
\text { masses with occasional infiltrative margins }\end{array}$ & $\begin{array}{l}\text { Increased cellularity with predominance of } \\
\text { inflammatory cells and myofibroblasic } \\
\text { proliferation }\end{array}$ & $\begin{array}{l}\text { Activin like kinase } \\
\text { positive, beta catenin } \\
\text { negative. }\end{array}$ \\
\hline
\end{tabular}




\section{Financial Support/Conflict of interest None}

\section{References}

1. Kempson RL, Fletcher CD, Evans HL, Hendrickson MR, Sibley RK (1998) Tumors of the soft tissues. Armed Forces Institute of Pathology, Washington

2. Tolan S, Shanks JH, Loh MY, Taylor B, Wylie JP (2007) Fibromatosis: benign by name but not necessarily by nature. Clin Oncol (R Coll Radiol) 19:319-326

3. Naylor EW, Gardner EJ, Richards RC (1979) Desmoid tumors and mesenteric fibromatosis in Gardner's syndrome: report of kindred 109. Arch Surg 114:1181-1185

4. Smith AJ, Lewis JJ, Merchant NB, Leung DH, Woodruff JM, Brennan MF (2000) Surgical management of intra-abdominal desmoid tumours. Br J Surg 87:608-613
5. Kasper B, Strobel P, Hohenberger P (2011) Desmoid tumors: clinical features and treatment options for advanced disease. Oncologist 16: 682-693

6. Reitamo JJ, Hayry P, Nykyri E, Saxen E (1982) The desmoid tumor.Incidence, sex, age and anatomical distribution in the Finnishpopulation. Am J Clin Pathol 77:665673

7. Yannopoulos K, Stout AP (1963) Primary solid tumors of the mesentery. Cancer 16:914-927

8. Faria SC, Iyer RB, Rashid A, Ellis L, Whitman GJ (2004) Desmoid tumor of the small bowel and the mesentery. AJR Am J Roentgenol 183:118

9. Levy AD, Rimola J, Mehrotra AK, Sobin LH (2006) From the archives of the AFIP: benign fibrous tumors and tumorlike lesions of the mesentery: radiologic-pathologic correlation. Radiographics 26(1):245-264

10. Melis M, Zager JS, Sondak VK (2008) Multimodality management of desmoid tumors: how important is a negative surgical margin? J Surg Oncol 98:594-602 